\title{
The effect of fuel mixture on engine vibrations
}

In the article, the authors analyze the effect of a fuel mixture (iso-octane, butanol and ethanol) on the generation of engine vibrations. The paper presents the results in the form of frequency response (using the Fast Fourier Transform - FFT) for three mixtures of different proportions. The measurements were made with the use of accelerometers and data acquisition cards, conditioning the received signal. The vibration component, in the form of acceleration, will be subjected to a FFT and presented in graphical form (periodogram). The authors put a special emphasis on a comparative analysis, indicating changes in harmonics, which may be a potential cause of engine degradation.

Key words: engine's vibrations, fuel mixture, FFT, frequency response

\section{Introduction: fuel mixture}

From the beginning of the introduction of the combustion engine, as the most popular method of supply engines, engineers sought optimal fuels. The direction of the search was multivariable (the extent of the influence of variables was mainly dependent on "political factors"). Initially, when the fuels were underdeveloped, they tried to obtain the most energy-efficient fuel, without taking into account the effects of such an operation. Today, research is conducted to maintain power while reducing toxicity of exhaust gases (unfortunately this is usually done by reducing one toxic factor, at the expense of increasing another). In addition to the energy and environmental aspects, one can notice and other problems resulting from the use of experimental fuel mixtures, such as changing the vibroacoustic deviation map of the engine. The article presents the results of tests of vibration changes in relation to the content of individual components of the fuel mixture.

Due to the fact that fuels available on the market contain an admixture of biofuels (alcohol) in research, it was decided to use iso-octane as a reference fuel to determine the octane number, RON (Research Octane Number) octane number equal to 100 .

Ethyl alcohol is one of the most available alternative fuels obtained in the treatment of biological waste. It is characterized by a higher octane number relative to commercial gasolines equal to 130 (RON), for gasoline 91-99, and a lower calorific value equal to $26.8 \mathrm{MJ} / \mathrm{kg}$ (calorific value of gasoline $42.6 \mathrm{MJ} / \mathrm{kg}$ ) Due to the high heat of evaporation $(0.92 \mathrm{MJ} / \mathrm{kg}$, gasoline $0.36 \mathrm{MJ} / \mathrm{kg})$ the addition of ethyl alcohol causes the cooling of the fuel and air mixture, increasing the density, thus increasing the fill factor. Butanol is one of the fuels that can be an alternative to fossil fuels. It is obtained in the biomass fermentation process. Physicochemical properties are similar to gasoline (calorific value $36 \mathrm{MJ} / \mathrm{kg}$, evaporation heat $0.43 \mathrm{MJ} / \mathrm{kg}$, RON 96). Butanol can be used as a replacement for gasoline without modifying engine components [1-3].

The mixtures were composed based on the experimental design for ternary mixtures. Due to the lower calorific value of alcohols relative to the reference fuel, fuel consumption with the use of mixtures is higher, while the improvement of the engine's ecological parameters can be expected due to lower temperatures achieved in the combustion process (reduction of $\mathrm{NO}_{\mathrm{x}}[3]$ ).

\section{Research object}

The object of the research was the Fiat 1,2 spark-ignited engine (capacity $1242 \mathrm{~cm}^{3}$, power $44 \mathrm{~kW}$ (60 horses), max torque $102 \mathrm{Nm}$, four-stroke engine, 8-valve, spark-ignition, powered by multipoint injection) [6]. The engine was located on the test bench of the electro-dynamic test bench, allowing it to control its parameters. The following figure shows the unit under test.

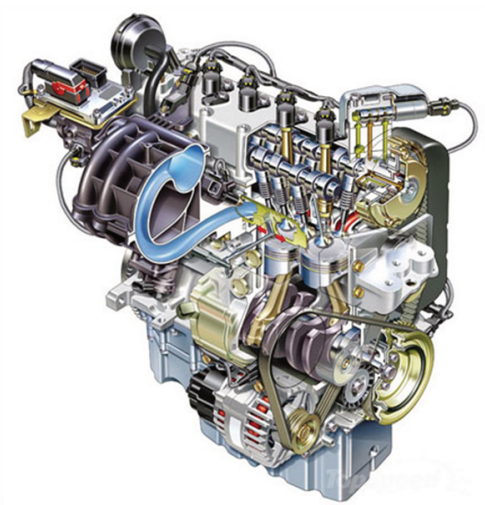

Fig. 1. Research object: Fiat 1.2 spark-ignition engine [3]

Fiat created a unit of 1.2 Fire in 1993. Over more than two decades, the motor has gained, among others, 16-valve head and was produced in four power versions. Drivers were dealing with a $60,75,80$ or 86 -horsepower spark ignition versions. The engine usually suffers from minor failures, well tolerates gas supply, and 8-valve models have collision-free timing. 1.2 Fire was mounted under the hood of two generations of Punto, Grande Punto, Bravo and Bravo, Palio, two generations of Panda, Stilo, Idea, Pentecost and Lancia Ypsilon and Y. This is a real sales hit that is really common in the aftermarket [4].

The facility was located on a measuring stand, equipped with an electrowired brake. The full schematic diagram of the position is shown in Fig. 2. 


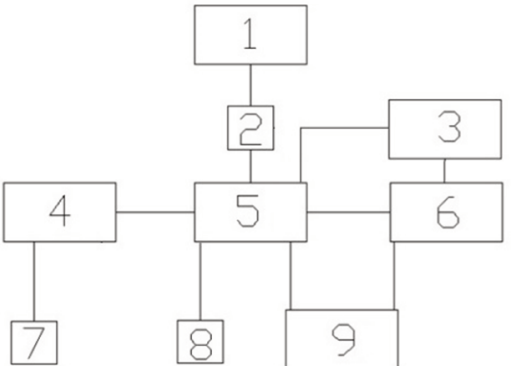

Fig. 2. Schematic diagram of the research place: 1 - fuel tank, 2 - fuel gauge, 3 - cooling system, 4 - exhaust system, 5 - engine, 6 - brake, 7 PEMS, 8 - accelerometer, 9 - driver

The measurements were based on proprietary diagnostic system based on single axis axial accelerometer PCB353A (sensitivity $10.19 \mathrm{mV} \pm 5 \%$, measuring range $\pm 491 \mathrm{~m} / \mathrm{s}^{2} /$ peak, frequency range 1 to $4000 \mathrm{~Hz} \pm 5 \%$, frequency range 0.7 to $6500 \mathrm{~Hz} \pm 10 \%$, resolution ( 1 to $10 \mathrm{~Hz}$ ) $0.0005 \mathrm{~g} \mathrm{RMS}$ for 1 to $10 \mathrm{~Hz}$ [5]). Accelerometer was connected to National Instruments type 9215 data acquisition card with USB connector (measuring range $\pm 10 \mathrm{~V}, 4$ multiplexed channels, max. sampling rate $100 \mathrm{kS} / \mathrm{s} /$ channel, 16 bit resolution [6]). The accelerometer was mounted along the vertical axis (perpendicular to the ground) on the head housing (8192 samples, $0.5 \mathrm{sec}$ ).

\section{Results}

Obtained signal (Fig. 3) is transformed to the frequency domain, using the fast Fourier transform with a base of 2 . The way in which the FFT algorithm is introduced has been known since 1965 and it is widely described in the literature [7-9]. The fast Fourier transform used for discrete signals is expressed as follows:

$$
X(k)=\sum_{j=1}^{N} x(j) \omega_{N}^{(j-1)(k-1)}
$$

The time domain response is showed below is related to two extreme measured values. Below (Fig. 4) is shown the frequency response of extreme values.

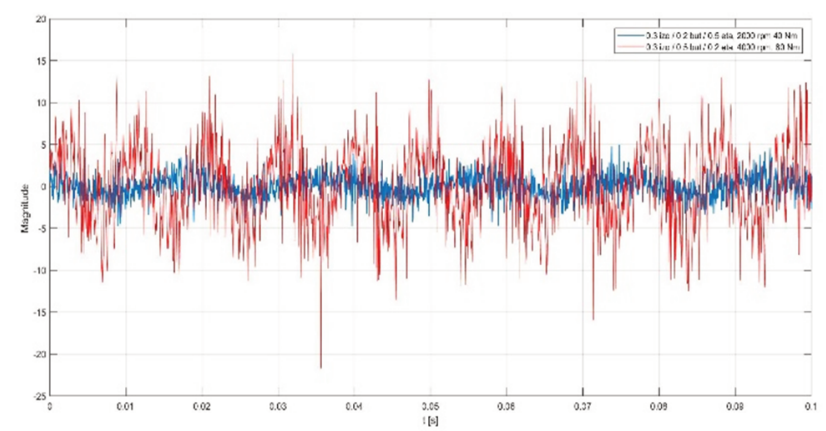

Fig. 3. Time response signal for extreme research values (blue - mixture of $0.3 \mathrm{izo} / 0.2$ but./0.5 eta, red $-0.3 \mathrm{izo} / 0.5 \mathrm{but} / 0.2 \mathrm{eta}, 2000 \mathrm{rpm}, 40 \mathrm{Nm}$ )

The table shown below shows the normalized values of magnitude as a function of frequency. The engine corresponds to 4 has basic harmonics. The first one is a direct derivative of the motor engine load (it is $51,78,105 \mathrm{~Hz}$ for the next 3 engine load states). Subsequent values of harmonic dominant frequencies (which are further derivatives of the motor load) are: 1200,3750 and $7000 \mathrm{~Hz}$.

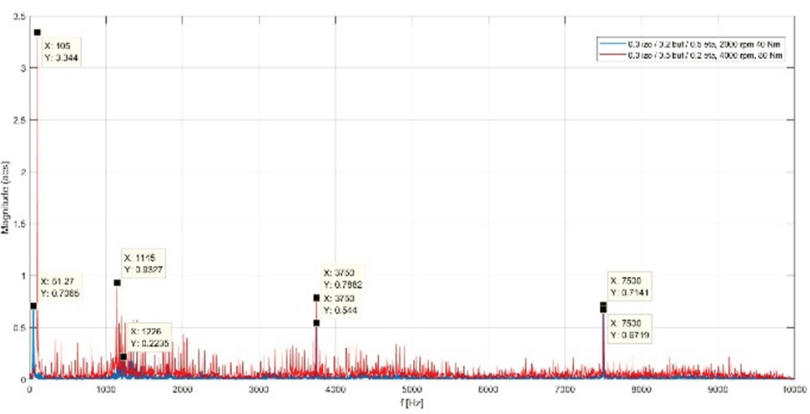

Fig. 4. Frequency response signal (periodogram) for extreme research values (blue - mixture of $0.3 \mathrm{izo} / 0.2 \mathrm{but} / 0.5 \mathrm{eta}$, red $-0.3 \mathrm{izo} / 0.5 \mathrm{but} / 0.2$ eta, $2000 \mathrm{rpm}, 40 \mathrm{Nm}$ )

Table 1. Amplitude values of 4 dominant harmonics (only in the first case there are frequency fluctuations depending on the load). The values are presented for mixtures of fuel: 0.3 isooctane $/ 0.2$ butanol $/ 0.5$ ethanol (red); $0.3 / 0.35 / 0.35$ (green) and 0.3/0.5/0.2 (blue)

\begin{tabular}{|c|c|c|c|c|c|}
\hline \multirow{2}{*}{} & \multicolumn{5}{|c|}{ Dominant harmonic no. } \\
\cline { 2 - 6 } & \multicolumn{2}{|c|}{1} & 2 & 3 & 4 \\
\hline $\begin{array}{c}\text { Engine's } \\
\text { load }\end{array}$ & $\begin{array}{c}\mathrm{f} \\
{[\mathrm{Hz}]}\end{array}$ & $\begin{array}{c}\text { Mag } \\
(\mathrm{abs})\end{array}$ & $\begin{array}{c}\text { Mag (abs) } \\
\mathrm{f}=1200 \mathrm{~Hz}\end{array}$ & $\begin{array}{c}\text { Mag (abs) } \\
\mathrm{f}=3750 \mathrm{~Hz}\end{array}$ & $\begin{array}{c}\text { Mag (abs) } \\
\mathrm{f}=7500 \mathrm{~Hz}\end{array}$ \\
\hline $\begin{array}{c}2000 \mathrm{rpm} / \\
40 \mathrm{Nm}\end{array}$ & 51 & 0.71 & 0.22 & 0.54 & 0.67 \\
\hline $\begin{array}{c}3000 \mathrm{rpm} / \\
60 \mathrm{Nm}\end{array}$ & 78 & 1.83 & 0.61 & 0.59 & 0.72 \\
\hline $\begin{array}{c}4000 \mathrm{rpm} / \\
80 \mathrm{Nm}\end{array}$ & 105 & 3.40 & 1.95 & 0.72 & 0.84 \\
\hline $\begin{array}{c}2000 \mathrm{rpm} / \\
40 \mathrm{Nm}\end{array}$ & 51 & 0.74 & 0.19 & 0.52 & 0.66 \\
\hline $\begin{array}{c}3000 \mathrm{rpm} / \\
60 \mathrm{Nm}\end{array}$ & 78 & 1.85 & 0.70 & 0.61 & 0.68 \\
\hline $\begin{array}{c}4000 \mathrm{rpm} / \\
80 \mathrm{Nm}\end{array}$ & 105 & 2.94 & 1.19 & 0.68 & 0.74 \\
\hline $\begin{array}{c}2000 \mathrm{rpm} / \\
40 \mathrm{Nm}\end{array}$ & 51 & 0.77 & 0.33 & 0.59 & 0.74 \\
\hline $\begin{array}{c}3000 \mathrm{rpm} / \\
60 \mathrm{Nm}\end{array}$ & 78 & 1.81 & 0.52 & 0.59 & 0.70 \\
\hline $\begin{array}{c}4000 \mathrm{rpm} / \\
80 \mathrm{Nm}\end{array}$ & 105 & 3.30 & 0.93 & 0.79 & 0.71 \\
\hline
\end{tabular}

The following figure shows changes in the absolute value of dominant harmonics depending on the fuel mixture (mix 1: 0.3 isooctane/0.2 butanol/0.5 ethanol, mix 2: $0.3 / 0.35 / 0.35$, mix $3: 0.3 / 0.5 / 0.2)$. The graph applies to all applications used (Fig. 5: $2000 \mathrm{rpm} / 40 \mathrm{Nm}$, Fig. 6: 3000 rpm/60 Nm, Fig. 7: 4000 rpm/80 Nm).

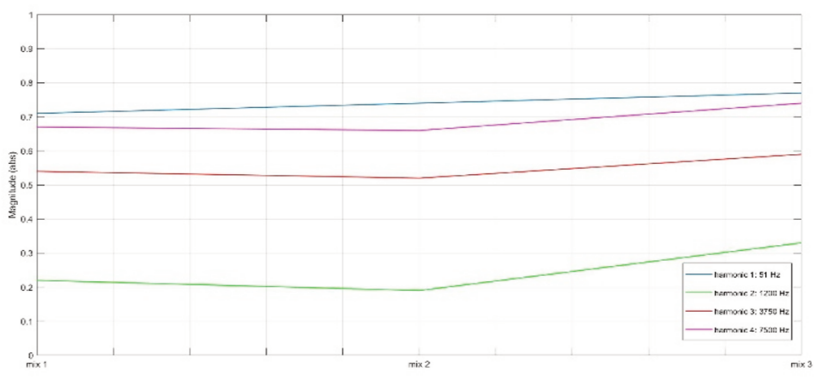

Fig. 5. Absolute values of dominant harmonics for 3 researches mixtures of fuel, $1^{\text {st }}$ load $(2000 \mathrm{rpm} / 40 \mathrm{Nm})$, blue: harmonic $1(51 \mathrm{~Hz})$, green: harmonic $2(1200 \mathrm{~Hz})$, red: harmonic $3(3750 \mathrm{~Hz})$, purple: harmonic 4 $(7500 \mathrm{~Hz})$ 


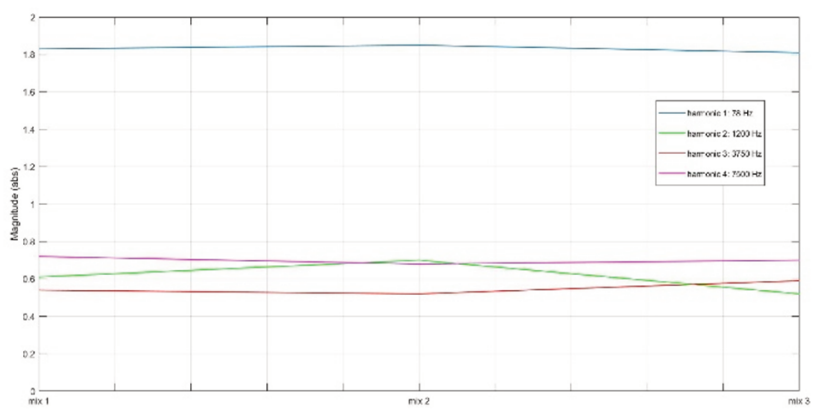

Fig. 6. Absolute values of dominant harmonics for 3 researches mixtures of fuel, $2^{\text {nd }}$ load $(3000 \mathrm{rpm} / 50 \mathrm{Nm})$, blue: harmonic $1(51 \mathrm{~Hz})$, green: harmonic $2(1200 \mathrm{~Hz})$, red: harmonic $3(3750 \mathrm{~Hz})$, purple: harmonic $4(7500 \mathrm{~Hz})$

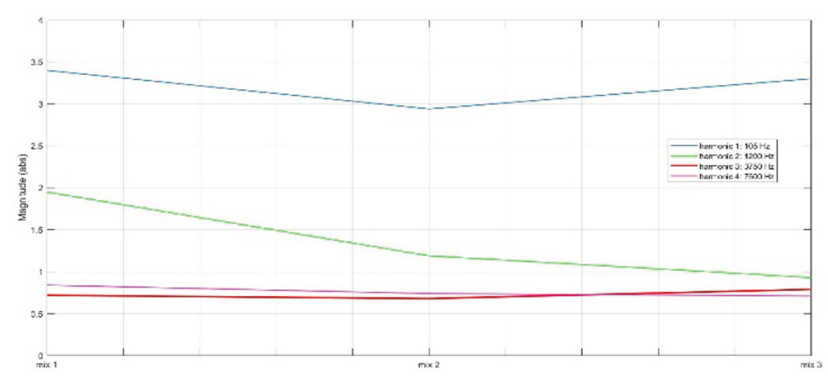

Fig. 7. Absolute values of dominant harmonics for 3 researches mixtures of fuel, $3^{\text {rd }}$ load $(4000 \mathrm{rpm} / 60 \mathrm{Nm})$, blue: harmonic $1(105 \mathrm{~Hz})$, green: harmonic $2(1200 \mathrm{~Hz})$, red: harmonic $3(3750 \mathrm{~Hz})$, purple: harmonic $4(7500 \mathrm{~Hz})$

\section{Conclusions}

The first dominant harmonic, which is a direct derivative of the engine load, takes on the largest size, regardless of the type of mixture used. The frequency value of this harmonic is variable and depends on the load, however, regardless of the type of mixture.

The last dominant harmonic (represented in Figures 5-7 in violet solid line), whose value is constant, regardless of the composition of the mixture $(7500 \mathrm{~Hz})$ generates high vibrations, but only for smaller load values.

The type of fuel mixture affects the fluctuations in the magnitude of the dominant harmonics, especially for small and large loads.

The biggest magnitude of vibration (the first dominant harmonic) generates a blend with the highest ethanol content. This conclusion applies to all loads tested (Table 1).

The mixture consisting of 0.3 isooctane $/ 0.35$ butanol/ 0.35 ethanol generates the highest vibration fluctuations. This can be a potential cause of engine degradation.

\section{Acknowledgements}

Research financed from Wroclaw University of Science and Technology statutory funds no. 0401/003/18.

\section{Nomenclature}

FFT Fast Fourier Transform

\section{Bibliography}

[1] CHMIELEWSKI, A., BOGDZIŃSKI, K., GUMIŃSKI, R. et al. The test stand research on Honda NHX 110 powered with alternative fuels: a case study. Advances in Intelligent Systems and Computing. 2019.

[2] FARIAS, M.S., SCHLOSSER, J.F., RUSSINI, A. et al. Performance of an agricultural engine using mineral diesel and ethanol fuels. Ciencia Rural. 47(3), e20151387, 2017.

[3] HUSSEIN, A.A. The effect of the heavy alcohol additive to base fuel of spark ignition engine. Raporty Wydziatu Mechanicznego Politechniki Wroctawskiej. Ser. PRE, 3. 140, 2017.

\begin{abstract}
Radosław Wróbel, DSc., DEng. - Faculty of Mechanical Engineering, Wroclaw University of Science Technology.

e-mail: radoslaw.wrobel@pwr.edu.pl
\end{abstract}

\footnotetext{
Łukasz Łoza, MEng. - Faculty of Mechanical Engineering, Wroclaw University of Science Technology. e-mail: lukasz.loza@pwr.edu.pl
}
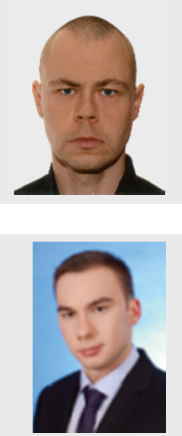

RON Research Octane Number
[4] An article about FIAT engines. fiatklubpolska.pl.

[5] PCB Homepage, Accelerometers. www.pcb.com/TestMeasurement/Accelerometers.

[6] NI9215 datasheet.www.ni.com/pdf/manuals/373779g.pdf.

[7] STRANNEBY, D. Cyfrowe przetwarzanie sygnałów. Metody, algorytmy, zastosowanie. Wydawnictwo BTC, Warszawa 2004.

[8] ZIELIŃSKI, T.P. Cyfrowe przetwarzanie sygnałów, Wydawnictwo WKŁ, Warszawa 2005.

[9] LYONS, R.G. Understanding digital signal processing. Wydawnictwo Prentice Hall, 2018.

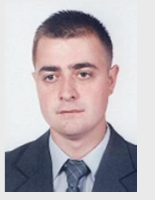

Radosław Włostowski, MEng. - Faculty of Mechanical Engineering, Wroclaw University of Science Technology.

e-mail: radoslaw.wlostowski@pwr.edu.pl 